University of Colombo Review (Series III),

Vol. 2, No. 1, 2021

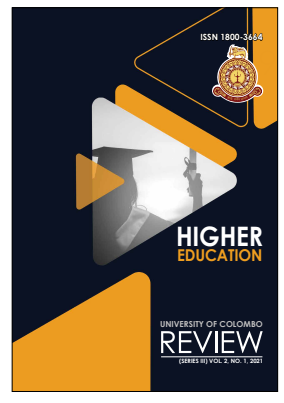

\title{
Learning to Learn with COVID-19: An Exploration into Sri Lankan Undergraduates' Attitudes and Experiences vis-à-vis Emergency Remote Teaching
}

\author{
Achala K. Dissanayake \\ Senior Lecturer, Department of English, CINEC Campus, Sri Laka
}

ABSTRACT
This article focuses on undergraduate students' experiences and
attitudes to Emergency Remote Teaching (ERT) during and after
the first COVID-19 lockdown in Sri Lanka, which began in March
2020. The pandemic triggered a shift from traditional educational
methods to online teaching and learning. For this transition to be
successful, the opportunities and challenges of online learning during
a pandemic should be studied. The article and its findings are based
on a questionnaire and Focus Group Discussion (FGD) with eighteen
undergraduates of a degree-awarding, non-state higher education
institute (NSHEI). Overall, the majority of students displayed a favorable
attitude to online education and a preference for blended learning in
the future. Advantages were reduced travel time and cost, punctuality,
the ability to attend lectures from comfortable surroundings, and the
availability of recordings of the lecture. Disadvantages were inadequate
internet facilities, devices, and training in the use of the internet and
the Learning Management System (LMS). Disrupted concentration
and motivation due to the absence of a good learning environment
was also reported, as were the limitations of the mobile phone as the
primary device for online learning, lack of face-to-face interaction and
immediate feedback/ clarification, COVID fatigue, and exam related
stress. Suggestions for overcoming these issues are provided at the
end of the article.

\section{KEY WORDS:}

Emergency Remote Teaching (ERT), online education, student engagement and motivation, COVID-19

Suggested Citation: Dissanayake A. K. (2021). Learning to Learn with COVID-19: An Exploration into Sri Lankan Undergraduates' Attitudes and Experiences vis-à-vis Emergency Remote Teaching. University of Colombo Review (New Series III). 2 (1). 79 - 101.

(c) 2021 The Authors. This work is licenced under a Creative Commons Attribution 4.0 International Licence which permits unrestricted use, distribution, and reproduction in any medium, provided the original work is properly cited. 


\section{Introduction}

With COVID-19 heralding the new norm, Emergency Remote Teaching (ERT) replaced traditional classroom-based education as the safest and most feasible mode of education. ERT can be defined as a form of distance education that takes place in times of emergencies, be it conflict situations (Burde et al., 2016; Shraim \& Khlaif, 2010), environmental disasters (Dhawan, 2020) or in times of health emergencies, including pandemics. In 2020, the speed at which in-class instruction was moved online due to the lockdown was "unprecedented and staggering," making the transition "stressful" for many instructors (Hodges et al., 2020). But, although ERT did entail online education, it did not involve choice. It was either $100 \%$ internet/ computer facilitated instruction or nothing at all, making online education a necessity rather than an option, a "panacea" in the present crisis (Dhawan, 2020, p. 2). This lack of option placed both university students and teachers in a difficult position, especially those with little or no access to the electronic hardware and software necessary for the teaching-learning process to take place on online fora. This article is based on a small-sample study which attempted to understand students' experiences and attitudes vis-à-vis ERT which still continues amid successive waves of COVID-19 in Sri Lanka.

The main objective of the research was to understand student experiences of online lectures and examinations during the COVID-19 lockdown and after, by investigating what they considered the advantages and disadvantages of online learning. Data was collected prior to the second wave, which commenced in early October, 2020, with the intention of understanding students' needs and suggestions for improvement in online education. Online education as a form of distance learning is now a must although, before the pandemic, it was a choice. Furthermore, the participants' university decided to conduct lectures online and offline even after higher education institutes re-opened in July 2020. This, however, was halted due to the second wave of COVID-19 in Sri Lanka.

By understanding students' concerns regarding online education, academic staff can take necessary steps towards providing students the necessary skills and information in the use of online education platforms used by lecturers and educational institutes. In addition, students' feedback on their online learning experiences is informative for improving teaching methods and aids towards better learning outcomes.

This article first discusses ERT as a form of online and distance education, and reviews research findings of studies conducted on online education both before and during the pandemic. It thereafter presents the research questions used in the study, the methodology and the limitations of the study, followed by a discussion of the findings along with suggestions to overcome the challenges of ERT and blended learning.

\section{Emergency Remote Teaching (ERT) During the Pandemic}

ERT combines both distance and online education. For education to be classified as online, it should involve an individual engaging with content and/or people through the internet, for purposes of learning. This learning process can be a component of a formal program or simply driven by the learners' self-interest. Online education is a branch of 
distance learning since it involves teaching where teacher and student are physically separated (Means et al., 2014). These learning experiences can occur in synchronous contexts (where interaction among the teacher and students happens simultaneously) or asynchronous contexts (where students interact with lesson material at their own pace) (Serdyukov, 2019). Since ERT in the present times aims at facilitating social distancing by moving the entire teaching/ learning process onto online fora, ERT is a combination of distance and online education.

ERT in the present context does not equal blended learning since face-to-face interactions are absent. Blended learning, by definition, is a convergence of online and face-to-face learning (Pearson, 2020) with the latter translating as "traditional learning" (Toronto School of Management, 2020), excluding videoconferencing.

Online education and ERT are not the same. ERT can be considered as the first of many steps taken towards the successful implementation of online education. In the present health emergency, due to the almost overnight shift to online education, ERT is characterized by an absence of careful planning (Hodges et al., 2020). Programs which were initially designed to be conducted in-class cannot be completed as effectively via the internet since the design of in-class programs of study, along with their delivery methods and assessment, would not suit or address the new dimensions that online education entail. Considering ERT and online education as one and the same thing could be a result of the two different forms of education being discussed only within the "world of educational technology and instructional design researchers and professionals" (Hodges et al., 2020). Misnaming ERT as online education can prove disadvantageous in the long run, since it would "seal the perception of online learning as a weak option" (Hodges et al., 2020). Therefore, the current face of education should be evaluated and recognized for what it is, which would enable the modification and eventual replacement of ERT with proper, wellplanned, online programs.

Analyzing the challenges faced by Pakistani medical colleges in delivering online education during the lockdown, Farooq, Rathore, \& Mansoor (2020) suggest that "the current scenario of COVID -19" be seen as an opportunity to "implement [online] teaching and learning methodology in the medical schools and training institutions" (p. 68). This sentiment is expressed regardless of the fact that online medical education is a "totally new experience" for most faculty members of different medical colleges and medical students in Pakistan (p. 67). Before COVID-19, the implementation of online education (almost forcibly as it is happening today) would have proved disastrous and unacceptable. However, given that the faculty and students had no choice but to transfer to the teaching/ learning process online, considering ERT as an opportunity is the most meaningful way of dealing with it. Furthermore, resistance to change will not benefit any educational institutes since they will be "judged on their pace to adapt to the changes in such a short period and their ability to maintain the quality" (Dhawan, 2020, p. 4). Adapting to change occurred quickly at Sri Lankan higher educational institutes. As of June 2020, "during the COVID-19 pandemic, more than $90 \%$ of higher education institutions (state and nonstate) [had] carried out remote learning (mostly online)" (Hayashi et al., 2020, p. 4). 
Maintaining the quality of online teaching and learning is time-consuming and requires a strengths, weaknesses, opportunities, and threats (SWOT) analysis of the education process currently taking place as ERT. Much research has been conducted into the strengths and weaknesses of online education both before and during the pandemic. However, from the articles reviewed for this study, only a very few of them refer to online education during the spread of COVID-19 as ERT. Some of the advantages of online education are location flexibility, comfortable surroundings and the ability to stay at home (Dhawan, 2020; Fidalgo et al., 2020). In addition to the choice of location, it was found that the students' ability to work at their own pace and manage their own study time were conveniences of online learning (Dhawan, 2020; Fidalgo et al., 2020). Other strengths are continuous access to online material, the availability of a range of courses and content, ability to receive immediate feedback (provided there is an interacting learning environment) and catering to a wide audience (Dhawan, 2020). Online education also makes it possible for larger student groups to be accommodated virtually and enables "the availability of remote lecturers who would otherwise travel long distances to deliver lectures especially in universities away from the capital city" (Karunathilake et al., 2020, p. 3). Therefore, if access to the necessary infrastructure is available to both students and lecturers, online education will transcend the limitations of time and location that are posed by a traditional educational process.

Technical issues are a common difficulty faced in online education. Lack of access to a proper internet connection (Adnan \& Anwar, 2020; Fidalgo et al., 2020; Hayashi et al., 2020; Karunathilake et al., 2020), costs that universities have to incur for internet connectivity (Karunathilake et al., 2020), repeated power failures (Farooq et al., 2020) and lack of access to equipment necessary for online education (Dhawan, 2020; Fidalgo et al., 2020; Hayashi et al., 2020) are some of the issues that both students and lecturers face where online education is concerned. Other issues relating to the sudden transition to online education are, low computer literacy skills, instructors' lack of knowledge about online platforms (Karunathilake et al., 2020) and low awareness of the dynamics of live online teaching, including instructional design and strategies used to maintain students' attention, and online assessment (Farooq et al., 2020). Students' lack of self-discipline and motivation too are factors that prevent online education from being effective (Adnan \& Anwar, 2020; Fidalgo et al., 2020). In addition, self-isolation and difficulty in interacting with peers and instructors are issues that students face (Adnan \& Anwar, 2020; Fidalgo et al., 2020). Online education, moreover, does not suit students who prefer synchronous faceto-face interaction with instructors (Adnan \& Anwar, 2020; Fidalgo et al., 2020).

The inability of lecturers to update their teaching strategies can lead to less student engagement in the online education fora (Farooq et al., 2020). This disinterest on the part of teachers could be attributed to personal challenges they face during lockdown. For instance, according to Farooq et al. (2020), "working from home and maintaining a worklife balance has become particularly difficult for the female faculty during this crisis all around the globe" (p. 68). Further research should be conducted into the extent to which women undergraduate and postgraduate students are troubled by the "study-work-life" balance during the pandemic. 
Measuring students' attendance during online sessions is another issue with ERT. For instance, students "may mark proxy attendance while engaging in other online activities at the same time" (Farooq et al., 2020, p. 68). In addition, I experienced instances when switching on the video on Zoom causes internet connectivity issues for both students and instructor. This contrasts with the views of Karunathilake et al. (2020) that most students and educators have observed that, due to online platforms being versatile and accessible, student attendance has risen to almost 100\%. Similarly, Benta et al. (2015) maintain that using an e-learning platform such as Moodle can increase university students' attendance and the submission rate of students' homework. However, it must be noted that in synchronous online sessions, attendance cannot be certain since, immediately after the instructor marks attendance, some students might be disconnected due to connectivity issues. The students' continuous presence and engagement cannot be ascertained. Additionally, even though students are present in a virtual classroom, their engagement with the lesson may be diminished due to background disturbances. Therefore, it is necessary for educational institutes to decide whether to focus solely on students' continuous physical presence in the virtual classroom, or to measure students' attendance based on engagement with the lesson material and asynchronous homework tasks. Formative assessments can be used for these purposes. In this sudden shift from traditional classrooms to e-classrooms, institutes are required to come up with new, clear-cut criteria for evaluating attendance.

Finally, developing students' soft skills such as empathy would prove tedious in online education (Karunathilake et al., 2020), although medical students would benefit, as online education would prepare them "to face a world where there is a high digital literacy rate and where their patients will also be well versant with the latest technologies and innovations" (p. 3). Therefore, though ERT during the pandemic leads students to explore new technologies thereby improving skills necessary for the 21 st century, the development of soft skills get neglected.

Online education amid the pandemic offers many pros and cons. The fact that it has become a necessity is both an advantage and a disadvantage. Necessity is the mother of invention; yet, when dealing with this necessity which requires massive levels of adaptation, certain groups of individuals who cannot keep up suffer. Therefore, alongside the necessity of a complete shift to ERT runs the need for understanding the difficulties of the students who use ERT.

\section{Methodology}

The study was based on the following research questions:

1. How did students attend online lectures, face online examinations and check email correspondence from their faculty during the COVID -19 lockdown?

2. What are students' attitudes towards online lectures and examinations?

3. In what ways would students have to prepare for blended learning (e.g.: acquiring internet connections/ receiving training in the use of online learning platforms) before the faculty decides to conduct both online lectures alongside in-class lectures in the future? 
4. What are the advantages and disadvantages of online lectures and examinations?

The eighteen participants who were a part of the study are undergraduates of a degree-awarding non-state higher education institute (NSHEI) and are currently in the second semester of the second year of the Bachelor of Arts in English degree program approved by the Sri Lankan University Grants Commission (UGC). All participants are English medium students, and their final examination of the previous semester were completed online.

Data collection was carried out in late September 2020, when universities had reopened for a brief period following the first wave of COVID-19. At the time the data was collected, the participants were receiving instruction in-class. Therefore, the students' responses to the questionnaire, and their opinions, experiences and suggestions shared in the focus group discussion (FGD) about ERT were provided in retrospect. The participants began receiving online instruction again in October 2020, due to the onset of the second wave of the pandemic in Sri Lanka. As the students reported at the FGD, all virtual lectures were conducted on Zoom and some recordings were uploaded on the learning management system (LMS). Some lecturers also emailed lecture notes and recordings to the students. Some handouts were also uploaded on the LMS. Attendance was not marked.

The 18 women undergraduates are within the ages of 23-25 years. They come from eleven districts, and six provinces, namely the Western, Central, North Western, Sabaragamuwa, Southern and North Central provinces. The districts are Colombo, Gampaha, Kalutara, Kandy, Matale, Nuwara Eliya, Kurunegala, Puttalam, Kegalle, Galle and Anuradhapura (see Table 1). Eight out of the participants are from the Western Province, with three students each from Colombo and Gampaha, and two from Kalutara. Three students hailed from the Central Province, with one student each from the districts of Kandy, Matale, and Nuwara Eliya. Three students came from the North Western Province with two of them from the Kurunegala district and one from the Puttalam district. Two participants are from the Kegalle district in the Sabaragamuwa Province, and one student each is from the Galle district in the Southern Province and the Anuradhapura district in the North Central Province.

Table 1 : Provinces and Districts Represented in the Student Sample

\begin{tabular}{|c|c|c|c|}
\hline Province & District & No. of Students & Total per province \\
\hline \multirow{3}{*}{ Western } & Colombo & 03 & \multirow{3}{*}{08} \\
\hline & Gampaha & 03 & \\
\hline & Kalutara & 02 & \\
\hline \multirow{3}{*}{ Central } & Kandy & 01 & \multirow{3}{*}{03} \\
\hline & Matale & 01 & \\
\hline & Nuwara Eliya & 01 & \\
\hline \multirow[t]{2}{*}{ North Western } & Kurunegala & 02 & \multirow{2}{*}{03} \\
\hline & Puttalam & 01 & \\
\hline Sabaragamuwa & Kegalle & 02 & 02 \\
\hline Southern & Galle & 01 & 01 \\
\hline North Central & Anuradhapura & 01 & 01 \\
\hline
\end{tabular}




\section{Instruments of data collection}

The research used a mixed methods approach and was exploratory in nature. Quantitative data was gathered using a questionnaire which was administered to the participants in class. The questionnaire consisted of 17 questions (Appendix A). Students were not required to state their names, and to safeguard participants' anonymity, they are not referred to in this article by their actual names.

Questions 1-3 of the questionnaire are regarding the students' age, hometown, and current year and semester at the university. Questions 4 and 5 focus on students' experience of following online courses before and after the COVID-19 lockdown. Questions 7-10 are about how students accessed the LMS, attended online lectures, faced online examinations, and checked email correspondence from their faculty. Questions 11-13 aimed at gauging students' attitudes towards online learning and examinations. Questions 6 and 14-17 related to the ways in which students would need to prepare for blended learning. The advantages and disadvantages of online learning were also discussed at a one-hour FGD which was conducted with all eighteen participants. The topics discussed in the FGD are provided in Appendix B.

\section{Limitations}

As Silva (2020) observes, "any social research technique that involves close physical proximity to the subjects, such as in-depth interviews will be difficult with social distancing and wearing of masks" (p. 2). Although this research did use the FGD method, one of its limitations was that, despite the ideal number of participants for focus groups ranging from 5-10, allowing all participants to make a "meaningful contribution to the conversation without things getting out of hand" (Flood, 2018, p. 139), I could not find extra time on the students' schedules to conduct several discussions. This complication arose as a result of the students being allowed on campus only for the purpose of attending lectures. Conducting an FGD online regarding the advantages and disadvantages of online lectures and examinations would not have been fruitful either.

While conducting the FGD, however, I attempted to minimize the discussion being dominated by a few confident participants. Questions were repeated and some students who were silent were encouraged to express themselves. Nevertheless, the limitations with regard to the FGD conducted have to be acknowledged, as have the limited number of research participants. Another limitation is the fact that the lecturer's experiences and opinions with regard to ERT are not discussed in this research. Due to these limitations, no generalizations are made based on the findings.

\section{Findings and Discussion}

\section{The Mobile Phone: The Device Most Used}

Answers received to questions 7-10 of the questionnaire reveal that the device most used by the students to check email, access the LMS, attend lectures, and upload assignments/ answer scripts is the mobile phone, followed by a combination of both mobile 
phones and personal laptops. These findings complement those of Hayashi et al.'s (2020), who found that $90 \%$ of the Sri Lankan university student population surveyed owned smartphones, while $55 \%$ of undergraduates in state higher education institutes and $66 \%$ at NSHEIs claimed to own a laptop.

Fifty-six percent of the participant population had used their phones to access the institutes' LMS during the lockdown, while $22 \%$ had used their laptops and phones. The mobile phone is, therefore, part of all other device combinations (Figure 1).

\section{Figure 1}

\section{Devices Used by Students to Access the LMS}
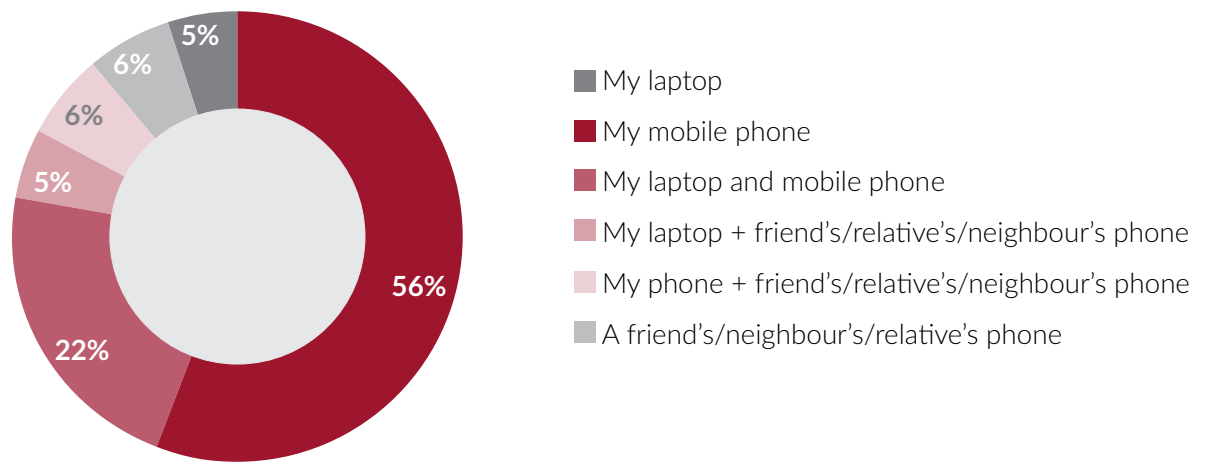

Where attending online lectures was concerned, 44\% (8) of the participants had used their mobile phones while $28 \%$ (5) had used a combination of their phones and laptops. Seventeen percent (3) had used only their laptops. As was the case with accessing the LMS, the most common device used for attending online lectures was the mobile phone (Figure 2).

\section{Figure 2}

\section{Devices Used by Students to Attend Online Lectures}

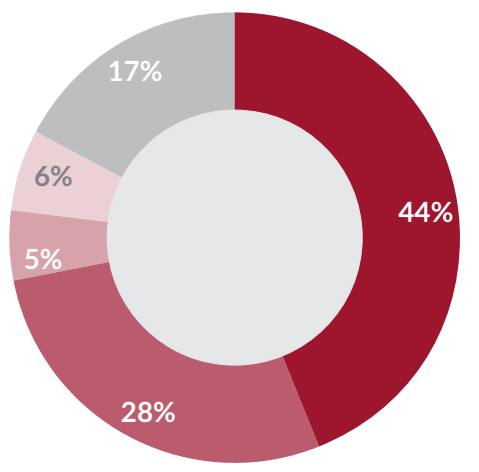

My laptop

My mobile phone

My laptop and mobile phone

My laptop+ friend's/relative's/neighbour's phone

My phone + friend's/relative's/neighbour's phone

Sixty-one percent (11) of students had used their mobile phones to access email. All device combinations involved the mobile phone (Figure 3). 


\title{
Figure 3
}

\section{Devices Used by Students to Access Email}

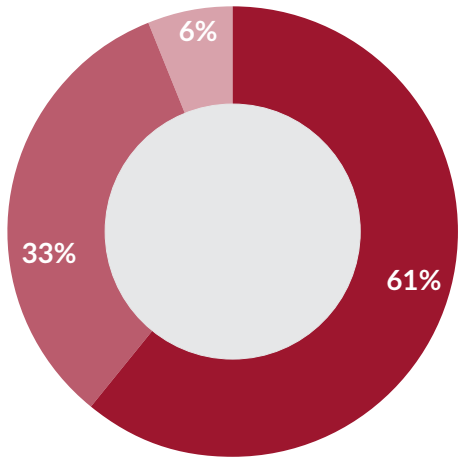

My mobile phone

My laptop and mobile phone

My phone + friend's/relative's/neighbour's phone

When uploading/emailing assignments/answer scripts, the majority of students $(72 \%)$ had used their mobile phones (Figure 4). This may have been because students were required to take pictures of the pages of their answer scripts and upload them as one PDF document onto the LMS. It would have been convenient to complete this process using the mobile phone.

\section{Figure 4}

\section{Devices Used by Students to Upload/ Email Assignments and Answer Scripts}

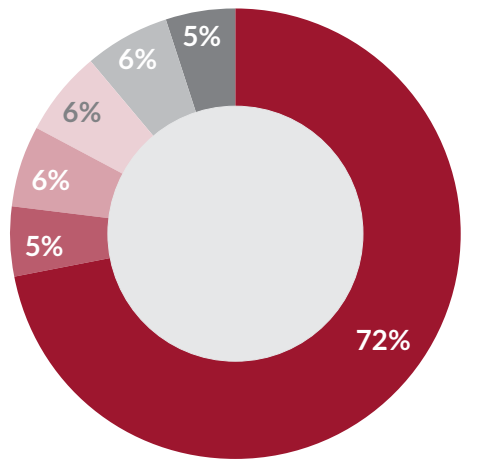

\author{
My laptop \\ My mobile phone \\ My laptop and mobile phone \\ My phone + friend's/relative's/neighbour's laptop \\ My phone + friend's/relative's/neighbour's laptop \\ My phone + friend's/relative's/neighbour's phone
}

On a few occasions, the students had sought help from a friend/ relative or neighbor. Yasini stated in the questionnaire that she used a friend's/ relative's/ neighbor's mobile phone to access the university's LMS and to upload her answer scripts/ assignments onto the LMS since the option of uploading was not available on her phone. Similarly, Ayesha, Sajani, and Jaanu sought help from a friend/relative or neighbor. Ayesha used her own laptop and a friend's phone to access the LMS and attend lectures. Sajani used her own phone and a friend's laptop to upload her answer scripts on the LMS. Jaanu had used her phone and a friend's phone to engage in all four activities described in Figures 1-4. Except in the case of Yasini, all other students had either their own laptops or their own mobile phones to attend to these activities. 
The fact that the device most students use is the mobile phone has implications for the design of each lesson plan on the part of the lecturer. Slides/ content shared on Zoom using the screen share option will not be clearly visible to students who attend lectures using mobile phones. As was observed by the students in the FGD, looking at length at the phone screen can strain the eyes unnecessarily. This is a point that needs to be taken into consideration by the instructors/ course planners. One of the ways in which this challenge can be avoided is to email the material that will be used in the live session to students well in advance, affording them time to familiarize themselves with the content and/or take print outs of the teaching aids.

\section{The Need for Better Internet Connectivity, Devices, and Training}

The answers to questions 6 and 14-17 of the questionnaire reveal that students have to purchase better internet connections and devices with which to attend lectures, and receive training in using the LMS and the internet. Although the students had access to a device through which to check email, access the LMS, attend lectures, and upload assignments/ answer scripts, half the number of students were either unhappy or very unhappy about their internet connections (Figure 5). Seventy-two percent of students will have to purchase a better internet connection if online learning continues (Figure 6). Moreover, 12 students $(67 \%)$ noted that they may have to purchase better laptops/mobile phones if the university decides to continue lectures online in the future (Figure 7). Kaveesha stated that the government should think of means by which university students from both private and public universities can be provided with laptops. This high percentage of students needing better internet connections could also be those who are boarders and, where there will be use of blended learning in the future, they would be required to purchase internet connections for their boarding places as well. Two out of the 7 students who stated that they are "less confident" in using the internet (Figure 8) noted that connectivity issues coupled with expense lessened their confidence in using the internet.

\section{Figure 5}

\section{Students' Satisfaction with the Internet Connection they Used to Attend Lectures}

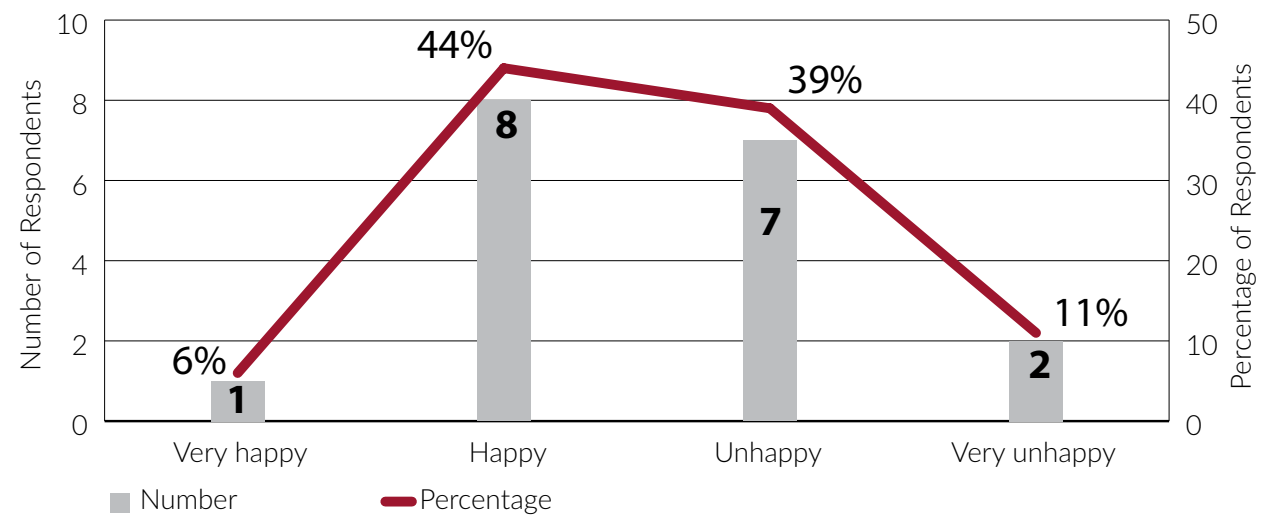


Figure 6

Students' Need to Purchase a Better Internet Connection

if Online Learning Continues

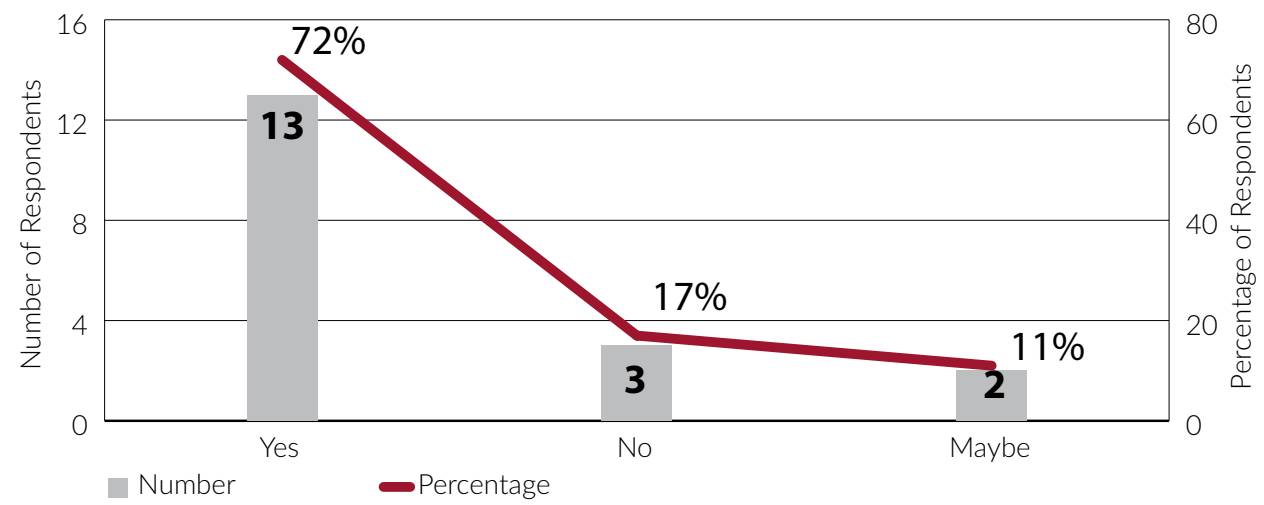

Figure 7

Students' Need to Purchase a Better Laptop/

Mobile Phone if Online Learning Continues

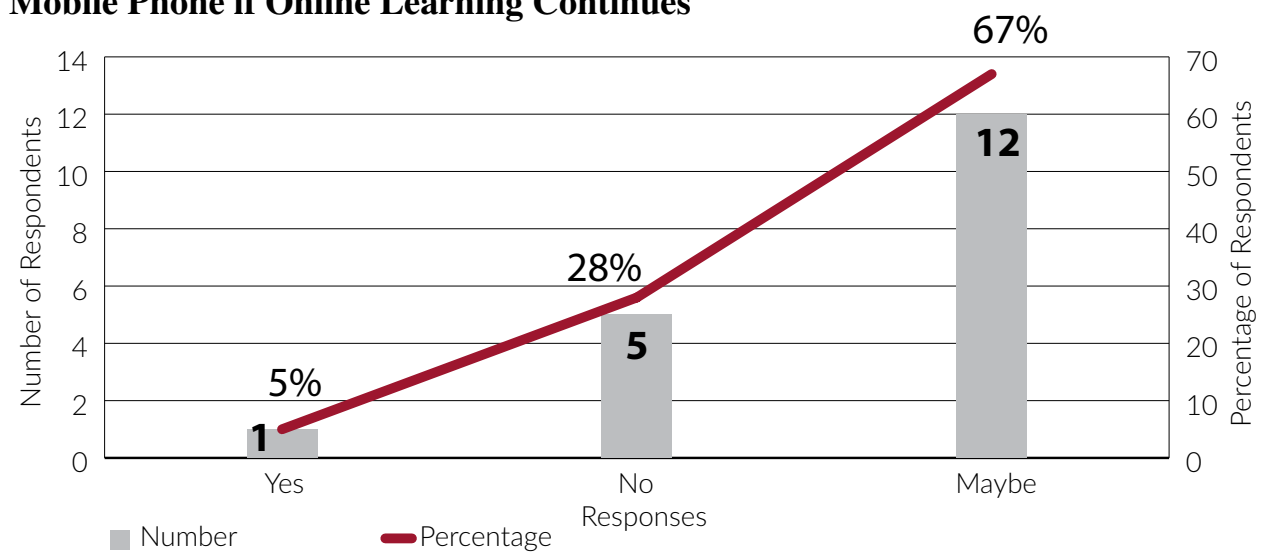

Figure 8

Students' Confidence in Using the Internet

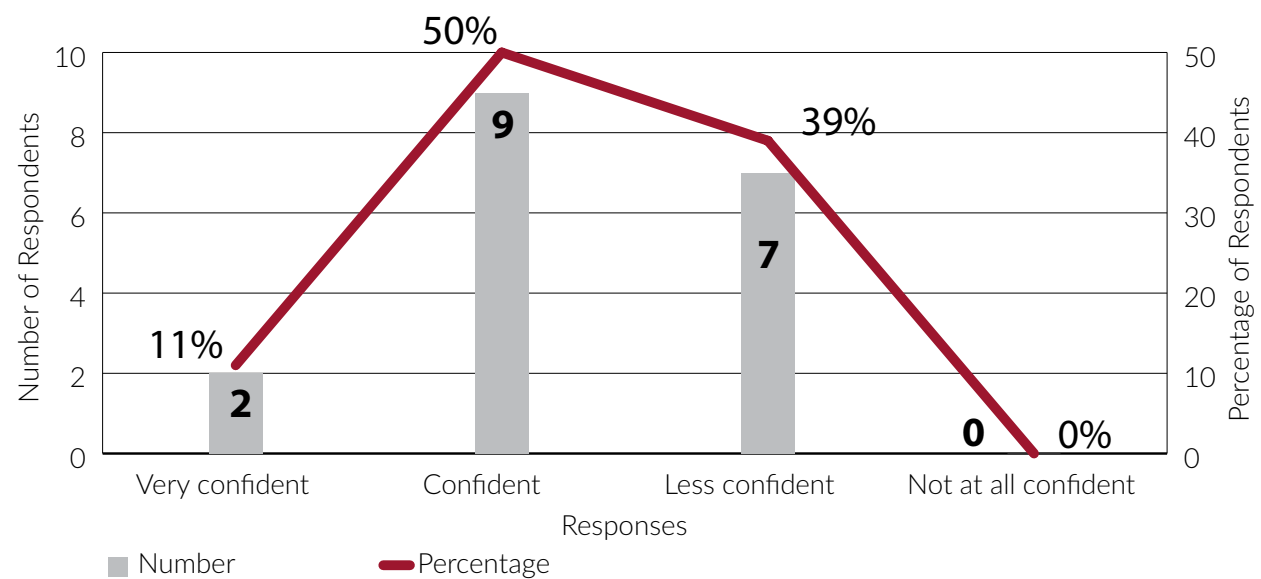


A total of 13 students were either very confident or confident in using the LMS (Figure 9). Jaanu and Safiya who are confident in using this system observed, however, that it took them a long time to log in and/or upload material onto the LMS due either to connectivity issues or because of the numbers of students logged into the system at the same time. Kesha underlined the fact that the LMS is an "easy method" of which she has to be more aware, and a system which has to be further developed due to its lack of speed. Pathumi claimed to be "not at all confident" in using this facility. Taking the above points into consideration, one can conclude that, in the face of the continuing delivery of instruction online, many of these students would have to purchase better internet connectivity packages, while a few would need to receive training in the use of the LMS and the internet. In addition, higher education institutions should develop the LMS further to minimize delays caused by internal traffic.

\section{Figure 9}

\section{Students' Confidence in using the LMS}

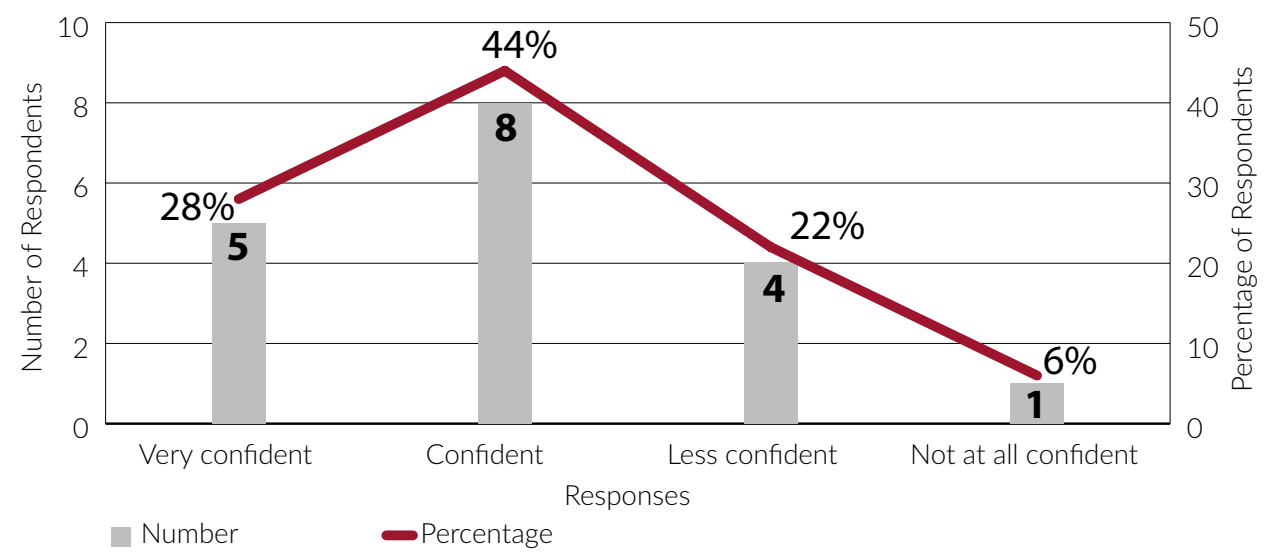

\section{Preference for a Mix of In-class and Online Lectures}

None of the 18 students had prior experience of following online courses before the pandemic. ERT during the present health crisis is their first experience of following courses on online fora. All participants reported that they had online lectures until two weeks prior to the day the data was collected (30th September, 2020).

All participants were either very happy (5 students, 28\%) or happy (13 students, $72 \%$ ) about their higher education institute conducting online lectures during the COVID-19 lockdown (Figure 10). In addition, 17 students (94\%) were either happy or very happy about the campus conducting online examinations (Figure 11). In the FGD, the students stated that they were happy that their examinations, which were postponed from March 2020, were held online without being postponed any further. However, Yasini who had stated in the questionnaire that she was unhappy with examinations being held online, highlighted that, 
[i]t is difficult to do online examinations. Not the answering of questions. But uploading the answer scripts. We were under a lot of pressure. As soon as we start writing the answers, we worried about if we will be able to log into the LMS / take clear images of each page of answer sheet/ upload our answers successfully/ convert images of our answers into PDF within the extra 30 minutes we were given to do all that. It was a stressful experience, especially since we were informed that our answer scripts will not be accepted if they had not been uploaded within the 30 minutes given.

The above quotation suggests that, apart from the exam related stress, students also worried about whether they would be able to successfully log into the LMS, download the question papers, and upload the answer scripts within the stipulated time.

\section{Figure 10}

Students' Satisfaction with University Decision to

Conduct Lectures Online during the Lockdown

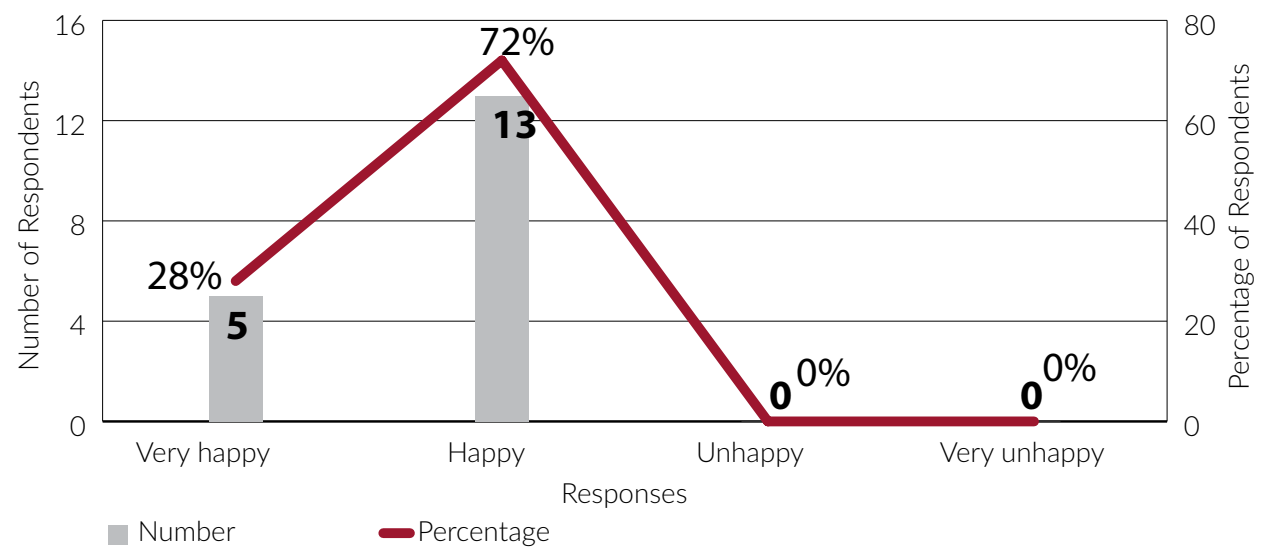

\section{Figure 11}

\section{Students' Satisfaction with University Decision to} Conduct Examinations Online during the Lockdown

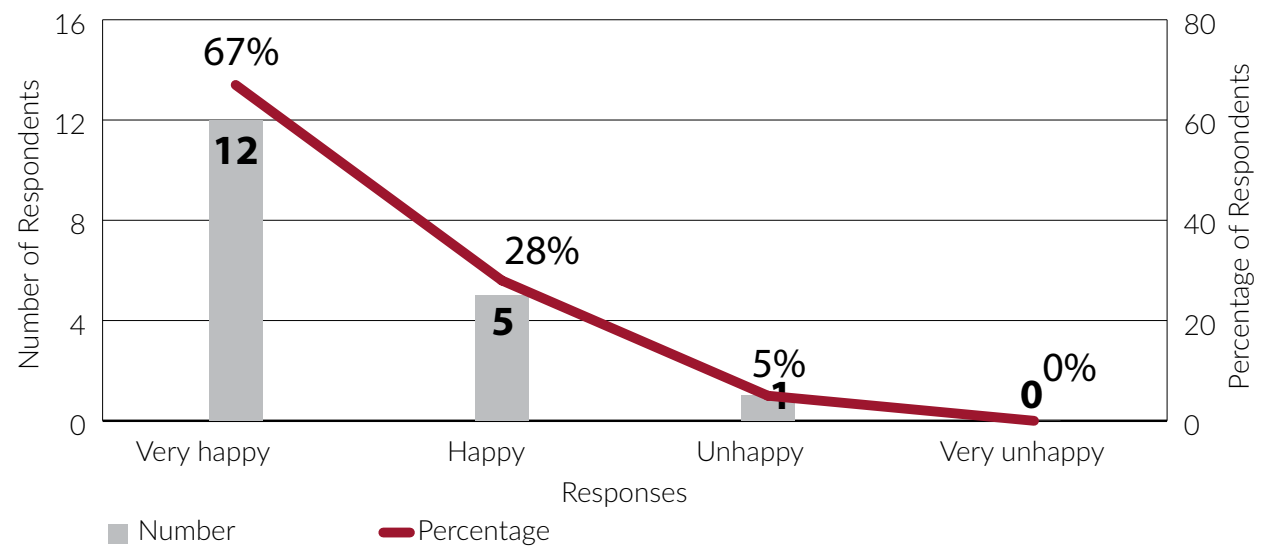


Despite facing difficulty where internet access and equipment were concerned, a majority of the students had a favorable disposition towards a combination of both online and in-class lectures. In response to Question 13 of the questionnaire, 5 students stated that they favor a mix of both in-class and online lectures in future (Figure 12). Eleven out of these 15 students, however, highlighted the importance of well-planned and conveniently scheduled lectures. This was further elaborated in the FGD where most students noted that there was much to be reaped through online education but that for these benefits to be enjoyed, online lectures should be better planned and scheduled.

Three students, however, displayed their preference for traditional classroombased learning by selecting the "100\% in-class option" (Figure 12). One of these students explained her choice by stating that "in-class lectures are more comprehensible" (Yasini).

\section{Figure 12}

\section{The Mode in which Students Prefer Lectures to be Conducted in Future}

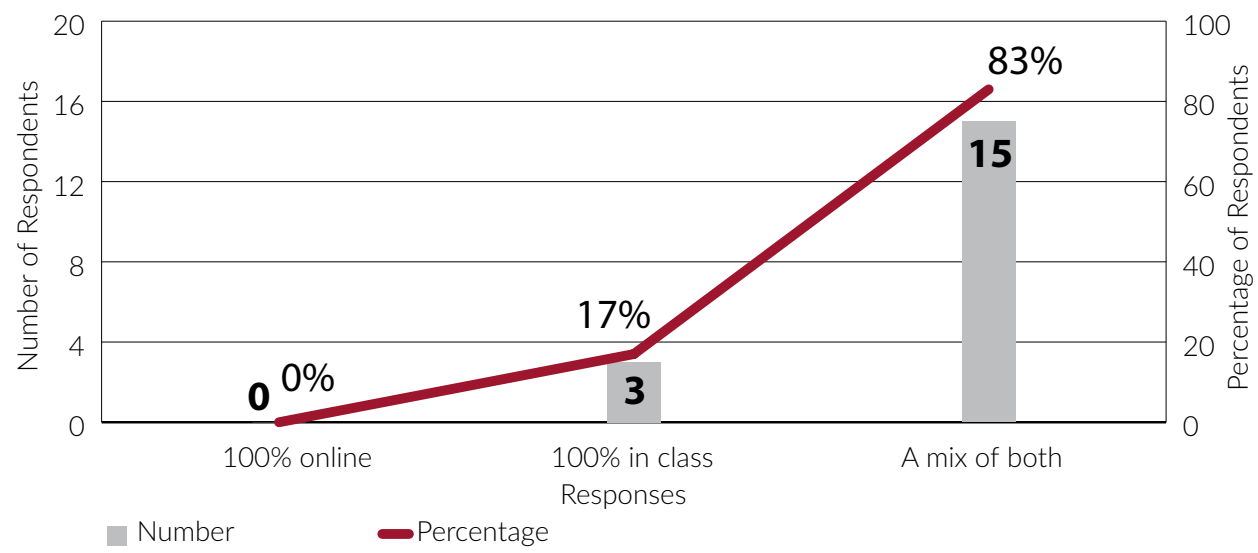

The data gathered through the FGD, coupled with the preference of 15 students for a blend of online and in-class lectures, and all 18 participants happy with the institute's decision to conduct online lectures indicates a favorable attitude, overall, towards online education. As Kaveesha, with whom all participants agreed, highlighted in the FGD:

It is important to have online lectures. If not, we will be in the stone age. We have to overcome problems and globalize. And there are $\mathrm{PhDs}$ and Masters programs available online. That is the reality of education today. So, this [ERT during the lockdown] has been a great experience for us. To overcome this, we need the facilities. Some people don't have internet. Also, if the lecturer can get the interaction from everyone during online lectures, lecture quality can be improved. Then we can be ready to face any future development, maybe even a second wave of COVID-19 or something similar to this situation. The government and institutes should get together and address such issues as financial difficulties and internet connections to provide data connections and other facilities. 
The above quotation suggests that these students consider their experience of ERT as a positive exposure which has prepared them for e-learning. Students are well aware of the opportunities digitalization of education offers them, and they consider the current experience of attending lectures online as a stepping stone towards becoming more familiar with the new face of education. Rather than making the lack of access to technology a hindrance, these students clearly prefer to move forward while successfully overcoming barriers that may come their way. This favorable attitude of students towards online education during the COVID-19 lockdown along with their preference for blended learning in the future are positive aspects that can be harnessed in the transition from traditional learning to ERT and thereafter to carefully designed programs in which a convergence of both in-class and online learning can take place.

\section{Pros and Cons of Online Education}

Advantages. The opportunity to reduce travel time and expenditure was considered as advantageous by all the research participants when discussing the pros and cons of blended learning in the future. Due to these advantages, students believe they can maintain punctuality when attending online lectures. Some students were also pleased that online lectures meant they did not have to pay for a boarding place. The ability to study from home also allowed students to attend lectures from comfortable surroundings. Furthermore, recorded lectures available on the LMS were a benefit to students.

For online education to be cost effective, however, careful planning and scheduling is required. The 18 research participants had online lectures till mid-September 2020 . Based on this experience, they highlighted that, if a mix of online and in-class lectures is implemented in future, the schedule should be carefully drawn up. Scheduling both in-class and online lectures in the same week would still require students who live far away to travel to their boarding places, thereby incurring expenses for both accommodation and travel. The participants also suggested that all handouts and lesson material be emailed to them prior to the lecture so they could make hard copies.

Disadvantages. A disadvantage of online lectures is the disruption of student engagement with the lesson. As mentioned earlier, these students had online lectures that were conducted via Zoom. Each lecture was interrupted by the 40-minute time out on Zoom and required students to rejoin the meeting. This interruption interfered with their concentration. In addition, the participants noted that sometimes, due to connectivity issues and heavy traffic on Zoom, there were significant delays in connecting and re-connecting with the e-lecture. These delays and the 40-minute limit, coupled with the knowledge that the recordings of the lectures would be available to them later in the day, demotivated the students, at times, from attending lectures.

Furthermore, the participants reported that those who attended online lectures using mobile phones lost concentration due to the text messages/notifications they receive from their network service providers and the apps they use. Phone calls from friends and relatives also created disruption. Students would sometimes mistakenly click notifications which would disconnect them from Zoom. Rejoining Zoom meetings when the lecture is ongoing 
does not give a good impression to the lecturer, resulting at times in the reprimanding of students for what is mistaken as late attendance and carelessness. Distractions in the form of notifications, text messages, and phone calls have also sometimes resulted in students forgetting to take down notes. Therefore, although the mobile phones did bring the world to their fingertips, they did not create the ideal environment for a virtual classroom.

The fact that the mobile phone was the most used device to attend online lectures also points to a lack of facilities. Nadhuni observed that some students only had one laptop at home which had to be shared among many siblings. This had resulted in such students attending lectures via their phone. One of the issues that Yasini had to face when using the phone was disruption "because the phone kept heating." So, she failed to concentrate on the lecture as she had to leave the virtual classroom sometimes because of this hardware problem.

The absence of a conducive learning environment at home was another issue reported by the participants. Students who had siblings with their own online lectures had difficulty concentrating on their lectures as there was no designated space in their homes designed specifically for online lectures. Parents too would unknowingly disturb the students by "coming into the room with our breakfast, lunch or tea," as Fazina and Dushani observed. What this demonstrates is the lack of a clear demarcation between domestic and study space in study-from-home contexts. Concentration was also disrupted because of what was described as a lack of knowledge among family and extended family members about the nature of online lectures and examinations. Yasini observed that "our examinations were held a few weeks after the initial lockdown was lifted, and that during their online examinations, my family had visitors. That caused me to lose concentration. They did not know what a stressful situation it is. Sri Lankans have no proper understanding of what online exams and lectures are."

In order to minimize adverse effects on students' concentration and motivation, each lecture session could be divided into 30/35-minute sessions with a break in-between each 40-minute Zoom meeting. Furthermore, with the involvement and assistance of the institution, lecturers could purchase and utilize more features offered by Zoom, such as the continuity of meetings beyond 40 minutes and Zoom Breakout Rooms. Lecturers could also use gamification to make the lecture sessions more interesting and engaging. Kahoot! is one example of gamification through which the lecturer can insert quizzes into the lecture session. However, any attempts at gamification that are not accessible via mobile phone should be avoided. Students also expect lecturers to be sensitive towards their circumstances, and lack of appropriate learning environments, technical issues such as slow internet connectivity and little or no access to laptops. The pandemic has affected all systems, education included, and it should be recognized that students and academic staff alike are adjusting to these sudden developments.

\section{The Challenges}

The absence of face-to-face interaction and the inability to request immediate feedback and clarification was another disadvantage of online lectures. Yasini, who prefers 
in-class lectures, stated that she "likes to see the lecturer's facial expression and body language and eye contact," without which it is difficult for her to discern the mood of the lecturer. Yasini's claim suggests that her lecturers did not have their video switched on, which may have been due to any internet connectivity issues that the lecturers might have faced. Whatever the reason may be, the lack of human connection has made these students reluctant to ask questions and obtain clarifications.

This reluctance was further heightened by the students being aware of the fact that they were in a virtual classroom in which each second of participation was being paid for. Therefore, cost inhibited students from asking for clarifications. Unlike in a traditional classroom in which the lecturers would offer clarification as and when necessary, or students had ample time to ask questions, in the virtual classrooms of which these students were participants, such opportunities were rare, if not absent. In addition, the traditional classroom assists with peer interaction whereas the participants of this research were unable to maintain much interaction with their peers in their online classrooms. Less opportunity to ask questions and seek clarification eventually led to less motivation and interest in the lesson. Knowing that the lecture recordings would be made available also reduced students' motivation to ask questions. The participants also stated that they missed campus life and interaction with their friends.

Low concentration levels were also reported. During online lectures, according to Hashani, knowing that the lecturer could not see if she was paying attention or not encouraged her to not even attempt to concentrate on the lesson. In addition, Dushani noted that, unlike prior to COVID-19, she had not engaged in self-study after the lecture. This maybe either due to lack of self-discipline, or self-motivation, or simply a result of students not being physically present in a campus environment. It could also be the result of the lecturer not having assigned students adequate self-study tasks with clear cut deadlines due to the sudden shift from traditional to online teaching.

Less self-discipline and self-motivation could also be attributed to COVID fatigue - the emotional stress and anxiety caused by the fear of the disease (NBC New York, 2020). The emotional stress is also due to the negative impact the pandemic has had on interpersonal, intra-family relationships, especially when curfew and/or a lockdown is imposed. Furthermore, COVID fatigue can be caused due to the economic impact of the pandemic. The Annual Report 2019 of the Central Bank of Sri Lanka reported that the extensive economic impact of the spread of the virus had caused "a loss of income and livelihoods for a large segment of society" (p. 21). Given that, according to the report, 60\% of those employed are engaged in the informal sector and 1.9 million are daily wage earners (p. 21), a large number of households have been economically affected by the pandemic. As Hashani observed (with the concurrence of the other students), breadwinners and families lost income and some students did not have access to WIFI or mobile data facilities. In addition, when curfew was imposed, students had no access to data cards. Not all students had online banking services, which made it impossible for them to pay for internet services. Therefore, as Hashani observed, students who could attend lectures did so, whilst those who were unable to do so due to the reasons above, were simply compelled to not attend 
lectures. In this context, even highly motivated students may not have had the means to focus on their studies.

In addition to COVID fatigue, participants revealed that exam related stress affected them direly. The end-semester examinations of the previous semester had been postponed since mid-March 2020. These examinations were held online in August 2020, taking into consideration the "Online Examination Assessment Guideline for DAIs" annexed to the Non-State Higher Education Circular No.01/2020 issued by the Ministry of Higher Education, Technology and Innovations. Accordingly, examination papers of three hours duration each, were uploaded on the LMS of the institute. The students could download the question paper 10 minutes before the starting time of the examination. All answers had to be handwritten, since, if the examinations had been conducted on campus, the students would have written the answers by hand. In addition, handwritten answers provide examiners a means of ascertaining that it was the student herself that answered the questions. The students were given an extra 30 minutes for taking images of pages of their answer script, converting these images into a PDF document, and uploading it on LMS. These examinations were the first of its kind that the faculty conducted using the LMS of the institute. Two mock tests were held prior to the actual examination to familiarize the students with the process.

Given these new requirements, the students were under intense pressure. Minuli stated that "in an exam hall we can continue writing until the last second since there is someone to take away the answer books from us." Unlike at on-campus examinations, students were unable to concentrate as they were worried about whether they would be able to log into the LMS or not, take clear images of each page of the answer script and upload the answers successfully. On occasions of failure to log in to the LMS, students had emailed the PDFs to the relevant lecturers.

\section{Next Steps}

This article, based on data from student participants, focused entirely on student perspectives of online teaching. Lecturers were not interviewed for the study. Nevertheless, there are several necessary steps lecturers can take to alleviate the above challenges faced by students. To begin with, switching on their videos while delivering lectures would encourage students to maintain active engagement, and make up for the lack of human interaction. Delivering lesson material at a slower pace, asking questions from students to ascertain their active learning, and providing clarifications are other necessities. When planning lessons conducted on online fora, more time should be allocated, therefore, for Q\&A sessions than at in-class lectures. Time also needs to be managed better so as not to incur extra expense. Faculty could also assign self-study tasks with clear cut deadlines and/or activities to complete before each session which would also give students a sense of direction and purpose. Communicating with students via email or another platform in between the sessions on clarifications would also encourage active learning.

The entire teaching program and course plans will also have to be revisited if intended learning outcomes (ILOs) are to be achieved. With any revisions to ILOs, amendments to the 
methods of assessment will have to follow. Online examinations have been stressful and not student-friendly. To address this, the structures of summative assessments and examinations need to be edited to suit the online medium. Essay questions may have to be replaced with MCQs or short answers. Depending on the nature of the subject and options provided on LMS, students assessments will have to be re-designed with the student foremost in mind.

To deal with these realities, patience and empathy are required on the part of the lecturers. Academic staff no doubt face similar challenges and would expect understanding to be reciprocated. The grave realities facing education today should be considered, however, as an opportunity to build upon, but this requires patience and a thorough assessment of the nature of ERT. A successful and complete transition from ERT to blended learning will require a robust assessment of the present, and this would mean working empathetically with all parties involved in the teaching/learning process.

\section{Conclusion}

This article was based on a small sample research study aimed at investigating students' experience of, and attitudes to ERT. The findings indicate that a majority of students used mobile phones to access lectures and the LMS, check email, and email/ upload their answer scripts and assignments onto the LMS. It was also found that students need better internet connections, devices, and training in using the LMS and internet.

The advantages of online learning were the ability to cut down on travel time and expenditure which also enabled punctuality. The ability to study from home also allowed students to attend lectures in familiar/comfortable surroundings. Furthermore, via the LMS, recordings of some lectures were made available to students - an advantage they would enjoy if blended learning becomes the norm in the future. The disadvantages were the disruptions to concentration and motivation, lack of face-to-face interaction and immediate feedback, COVID fatigue, exam related stress, and lack of proper planning and scheduling of lectures.

The findings also highlight many areas that require improvement in order to make ERT and blended learning a useful, enjoyable, and rewarding experience to both the students and lecturers. As the majority of the students use mobile phones for educational purposes, visibility is on a small screen, as opposed to a larger image and script on a laptop. Staring at the phone screen at length can also cause eye strain. Handouts and lesson materials should be circulated beforehand, therefore, so that students can familiarize themselves with the content and even make hard copies of the documents. Students should also be provided subsidized internet facilities and laptops to ease their transition from traditional to blended learning in the future. Lecturers should keep their videos on to provide human contact and encourage questions and requests for clarifications from students, speak at a slower pace, and devote more time for Q\&A. Self-study tasks in between sessions such as in-class quizzes (gamification) and homework can be included. This would give students a sense of direction and purpose, and increase motivation. Structures and duration of examination papers, and marks allocation are also matters that require adjusting, taking into consideration the nature of the online platforms through which student submissions 
of answer scripts/assignments have to take place. There is much at stake, therefore, in adjusting to the educational landscape that has been radically altered by the pandemic.

\section{References}

Adnan, M., \& Anwar, K. (2020). Online learning amid the COVID-19 pandemic: Students' perspectives. Journal of Pedagogical Sociology and Psychology, 2(1), 45-51.

Benta, D., Bologa, G., Dzitac, S., \& Dzitac, I. (2015). University level learning and teaching via E-learning platforms. Procedia Computer Science, 55, 1366-1373. https://doi.org/10.1016/j.procs.2015.07.123

Burde, D., Kapit, A., Wahl, R. L., Guven, O., \& Skarpeteig, M. I. (2016). Education in emergencies: A review of theory and research. Review of Educational Research, 87(3), 619-658. https://doi.org/10.3102/0034654316671594

Central Bank of Sri Lanka. (2020). Covid-19 and Sri Lanka: Challenges, policy responses and outlook. Annual report for the year 2019 (pp. 21-23).

https://www.cbsl.gov.lk/sites/default/files/cbslweb_documents/publications/annual_report/2019/ en/13_Box_02.pdf

Dhawan, S. (2020). Online learning: A panacea in the time of COVID-19 crisis. Journal of Educational Technology Systems, 49(1), 1-18. https://doi.org/10.1177/0047239520934018

Farooq, F., Rathore, F. A., \& Mansoor, S. N. (2020). Challenges of online medical education in Pakistan during COVID-19 pandemic. Journal of the College of Physicians and Surgeons Pakistan, 30(6, Supp. 1), 67-69. https://doi.org/10.29271/jcpsp.2020.Supp1.S67

Fidalgo, P., Thormann, J., Kulyk, O., \& Lencastre, J. A. (2020). Students' perceptions on distance education: A multinational study. International Journal of Educational Technology in Higher Education, 17(1) Article 18. https://doi.org/10.1186/s41239-020-00194-2

Flood, J. M. (2018). Wiley practitioner's guide to GAAS 2018: covering all SASs, SSAEs, SSARSs, $P C A O B$ auditing standards, and interpretations. Wiley.

Hayashi, R., Garcia, M., Maddawin, A., \& Hewagamage, K. (2020). Online learning in Sri Lanka's higher education institutions during the COVID-19 pandemic. ADB Briefs. http://dx.doi.org/10.22617/BRF200260-2

Hodges, C., Moore, S., Lockee, B., Trust, T., \& Bond, A. (2020, March 27). The difference between emergency remote teaching and online learning. Retrieved October 10, 2020, from https://er.educause.edu/articles/2020/3/the-difference-between-emergency-remote-teachingand-online-learning 
Karunathilake, I. M., Dissanayake, V. H., Yasawardena, S., Abegunawardena, A., Raviraj, S., Wijesinghe, P. S., Anthony, A. A., Wijesinghe, R. A. N. K., Bowatte, S., Wickramaratne, N., Pathirana, K. D., Pilapitiya, S., Edirisinghe, S., Hettiarachchi, D., Kohombange, C., \& Olipeliyawa, A. (2020). The new normal of medical education - challenges and opportunities. South-East Asian Journal of Medical Education, 14(1), 2-5. http://doi.org/10.4038/seajme.v14i1.241

Means, B., Bakia, M., \& Murphy, R. (2014). Learning online: What research tells us about whether, when and how. Routledge.

NBC New York. (2020, October 21). Mental, emotional stress caused by 'COVID fatigue' is serious problem, Cuomo says. Retrieved October 24, 2020, from

https://www.nbcnewyork.com/news/coronavirus/cuomo-says-mental-emotional-stress-causedby-covid-fatigue-is-serious-problem/2680467/

Ministry of Higher Education, Technology and Innovations, Specified Authority. (2020). Online Examination Assessment Guideline for DAIs (Non-State Higher Education Circular No. 01/2020(ii)).

Pearson. (2020, July 3). Online vs. blended learning: Which is better? Retrieved October 29, 2020, from

https://www.pearson.com/asia/insights-and-ideas/articles/2020/07/online-vs--blended-learning-which-is-better--.html

Serdyukov, P. (2019). Asynchronous/ synchronous learning chasm. In C. M. Sistek-Chandler (Ed.) Exploring online learning through synchronous and asynchronous instructional methods (pp. 1-33). Information Science Reference. https://doi.org/10.4018/978-1-7998-1622-5.ch001

Shraim, K., \& Khlaif, Z. (2010). An e-learning approach to secondary education in Palestine: Opportunities and challenges. Information Technology for Development, 16(3), 159-173. https://doi.org/10.1080/02681102.2010.501782.

Silva, K. T. (2020). Opportunities and challenges for social sciences in the aftermath of the COVID-19 pandemic. Sri Lanka Journal of Social Sciences, 43(1), 1-4.

http://doi.org/10.4038/sljss.v43i1.8122.

Toronto School of Management. (2020, July 14). Why 2020 is the year of blended learning. Retrieved October 29, 2020, from

https://www.torontosom.ca/blog/why-2020-is-the-year-of-blended-learning 


\section{Appendix A}

\section{Questionnaire}

1. Age

2. Hometown

3. Year and Semester

4. Did you follow any online courses before the COVID-19 lockdown?

5. Do you still have online lectures?

6. During the lockdown, how happy were you with your Internet connection that you used to attend lectures/ read emails etc.? (Very happy/ happy/ unhappy/ very unhappy/ other)

7. How did you access the LMS of your university during the COVID-19 lockdown? (My own computer/ laptop; my own phone; a friend's/relative's/ neighbour's laptop; a friend's/relative's/ neighbour's phone; other)

8. How did you attend online lectures during the COVID-19 lockdown? (My own computer/ laptop; my own phone; a friend's/relative's/ neighbour's laptop; a friend's/relative's/ neighbour's phone; other)

9. How did you access your email during the COVID-19 lockdown? (My own computer/ laptop; my own phone; a friend's/relative's/ neighbour's laptop; a friend's/relative's/ neighbour's phone; other)

10. How did you upload your assignments/answer scripts? (My own computer/ laptop; my own phone; a friend's/relative's/ neighbour's laptop; a friend's/relative's/ neighbour's phone; other)

11. How happy are you that your university conducted online lectures during the lockdown? (Very happy/ happy/ unhappy/very unhappy/ other)

12. How happy are you that your university conducted online examinations during the lockdown? (Very happy/ happy/ unhappy/very unhappy/ other)

13. In future, how would you prefer lectures to be conducted? (100\% online/ $100 \%$ in-class/ A mixture of both/ Other)

14. How confident are you in using the Internet? (Very confident/ Confident/ Less confident/ Not at all confident)

15. How confident are you in using the university LMS? (Very confident/ Confident/ Less confident/ Not at all confident

16. If your institute decides to continue online lectures/ examinations, would you need to buy a better Internet connection to attend lectures/ examinations? (Yes/ No/ Maybe)

17. If your institute decides to continue online lectures/ examinations, would you need to buy a better computer/ laptop/ mobile phone to attend lectures/ examinations? (Yes/ No/ Maybe) 


\section{Appendix B}

\section{FGD topics}

1. Number of subjects taught online

2. Did all lecturers follow the same procedure in terms of the online platform used and making the recordings of lectures available?

3. Advantages of online learning

4. Disadvantages of online learning 